\title{
Innovation Capability Model and Co-Creation as an Improvement of SMEs Performance
}

\author{
Naili Farida ${ }^{1}$, Sari Listyorini ${ }^{2}$ \\ \{nailifarida@lecturer.undip.ac.id ${ }^{1}$ \} \\ Universitas Diponegoro, Indonesia ${ }^{1,2}$
}

\begin{abstract}
The creative industries of Small and Medium Enterprises (SMEs) in the field of guitar manufacturing, currently the sales condition has decreased. To overcome these conditions, product innovation capability and collaboration between consumers and producers is needed. SMEs must provide innovation for the sustainability of product marketing to meet customer needs. Collaboration in Co-Creation between consumers and producers can improve the marketing performance of SMEs including things about product design, raw materials, and markets for new products, as an effort to increase marketing. The population in this study is the owner of SMEs in the creative industry with a total sample of 60 people. The Purposive sampling technique and analysis technique are applied by using SEM-PLS. The findings of this study indicate that innovation capability has a significant effect on marketing performance. Furthermore, Co-Creation and valuebased selling and innovation capability have a significant effect on market performance. With Innovation and Co-Creation Capability can improve SMEs marketing performance.
\end{abstract}

Keywords: Co-Creation, Selling Value Based Selling, Innovation Capability, Marketing Performance, SMEs

\section{Introduction}

Collinson and Wang [1], it is explained that capacity innovation is the ability of companies and components of the company in design innovation, marketing innovation, and production innovation continuously. It is accordance with the excellence of company-owned resources. According to Colurcio et al. [2], the theory with S-D-L underwent a continuous change in the way to flounder. It is concerning to market-related theory. Co-creation Value can support this market theory, so it takes the development of a theoretical framework that is relevance to the concept of service exchanges, resource integration, value creation, value determination, and institutions/ecosystems. In addition, there are research opportunities for the theory to middle range theory in the field of as follows: (1) development and implementation of the Strategy (2) The application of economic complexity and (3) The service study of cognitive mediators as a heuristic tool in the complex service ecosystem.

In addition, there are opportunities to use the S-D logic as a broader framework for macro marketing studies, including ethics, economics, environmental and social sustainability, as well as public policy. In addition, Collinson and Wang [1] explained that The capacity of innovation is the company's and component's capabilities in design innovation, marketing innovation, and continuous production innovation in accordance with the company's resource excellence. It was supported by Töytäri and Rajala's opinion [3] stating that creating excellent customer value is the company's progress to manage resources in order to be superior and able 
to survive in a competitive market. The company's success is measured by marketing performance, which is influenced by the innovation capabilities variable, Co-Creation and value based selling capability.

\section{Literature Review}

Innovation Capability according to Kavanagh, Walther and Nicolai [4] namely product innovation, process innovation, administrative innovation, marketing innovation and service innovations that have relevance and mutually synergistic with Customer Relationship Marketing or CRM include information, customer engagement, long-term partnerships and customer-based troubleshooting to improve business performance. Further, according to Aryanto, Fontana and Afiff [5] stated that the company will improve and manage the innovation process from generating ideas to commercialization, key factors in the innovation process are human resources being the main factor as an element in the innovation process. Moreover, Töytäri and Rajala [3] mentioned if creating a superior customer value is the company's progress to manage resources in order to be superior and able to survive in a competitive market.

Blocker, Cannon, Panagopoulos and Sager [6] stated value based selling capability, the strategy has two processes namely Create and allocate value related to the Exchange. Salespeople have a unique opportunity to explain the values that customers want to the company. The salesperson creates, maintains, and allocates the value of the relationship between the seller and the buyer. Research findings from Prahalad and Ramaswamy [7] demonstrate the customer value creation strategy as avenue for long term survival for the company and the effective implementation of the Company's Value to salespeople. There are three main factors of value-based sales dimension i.e., 1) customer business model, 2) craft value proposition and 3) communicate customer value. Prahalad and Ramaswamy [7] explained that the concept of the product that is now transformed into a co-creation concept has a high benefit compared to the product. It is reflected in the product value concept created by the company, while on the concept of co-creation products are created between the company and the customer. Findings of research results from Farida, Naryoso and Yuniawan [8] explained that co-creation has a significant influence on innovation.

According to Farida [9] explaining that marketing performance is the key to the success of a business as a result of market strategy for customers, market, financial gain for the organization. Marketing performance includes sales and growth, market share and market development. Findings of research results from Wiklund and Shepherd [10], The marketing performance is to have 4 indicators namely a. growth in sales volume, b. Growth of subscriber count, c. Growth of profit amount and d. Growth of market share.

a) Co-Creation Relationship to Innovation Capability

Prahalad and Ramaswamy [7] explained that the concept of the product that is now transformed into a co-creation concept has a high benefit compared to the product. It is reflected in the value of the product concept created by the company, while on the concept of co-creation products are created between the company and the customer. Findings of research results from Farida, Naryoso and Yuniawan [8] explained that cocreation has a significant influence on innovation. Results show that the higher the cocreation then the higher the innovation capability. 
b) Relationship Value Based Selling Capability to Capability innovation

Duncan, Jones and Rawson [11] explained that sales management in doing synergy on the external environment is the consumer so that the company is able to survive in the market, this is due to the new trend of value-based management and consumer demands and opportunities that require adaptation of the company. Further according to Tsai, Liao and Hsu [12] companies should be able to understand what the customer needs so that it can be fulfilled through the innovation process that is product design innovation produced and acquire essential design according to the wishes of the customer by using extensive analysis and extension transformation to be able to produce new product.

c) Relationship Capability innovation to marketing performance Innovation capacity according to Lawson and Samson [13] was an ability to make changes and ideas about new products, processes and systems for the benefit of the company and its stakeholders, as well as innovations according to Cleff and Rennings [14]. Product innovation effects of the environment in consideration of market interests and adapts to the market segments of the product innovations offered. Marketing Performance According to O'Sullivan and Abela [15] was the marketing performance influenced by the mind, knowledge as well as consumer behavior of customers so that it can affect the company's performance can be concluded that the increasingly high capability innovation will be followed by the higher marketing performance of the company.

d) Relationship Co-Creation to Marketing Performance

Findings of research related to Co-creation are very beneficial for both the company and its customers. Co-creation with customers to be a new source of competence for business strategy [7]. Co-creation makes the company interact with its customers for the suppression of co-creation with the customer may not only positively impact of the service capabilities, but also have a direct impact on the ability of the promotion, which is significantly different from the traditional [16]. Other than that other benefits of conducting coordination are gaining new competitive capabilities, which can appropriately be able to deliver a target customer and use data to make a unique approach [17]. Research finding from Farida and Ardyan [18] showed that there is a significant influence between co-creation and marketing performance significantly.

e) Value Based Selling Relationship to Marketing Performance

The product-oriented approach is an old pattern, the current era of marketing-oriented approach to consumers and quality of service is a priority. According to Töytäri et al. [19] mention in the business in the process of writing a doctorate into a customer centered on the creation of value. In line with Hung, Lu and Lee [20]. Sellers are able to interpret and communicate the proportions of existing values so that they can represent the value of naming including the value of time and effort of the customer. Research findings conducted by Alexander and Jaakkola [21] demonstrated that in the individual practice and managerial related to sales based on value will be a necessity in the competitive environment so that it takes effectiveness and efficiency of the resource in the company's needs and the expectation of consumers continuously.

\section{Hypothesis}

H1: There is influence Co-creation against Innovation Capability.

H2: Influence of Value Based Selling on Capability innovation. 
H3: The influence of Capability innovation on marketing performance.

H4: Effect of Co creation on marketing performance.

H5: There is a Value Based Selling influence on marketing performance.

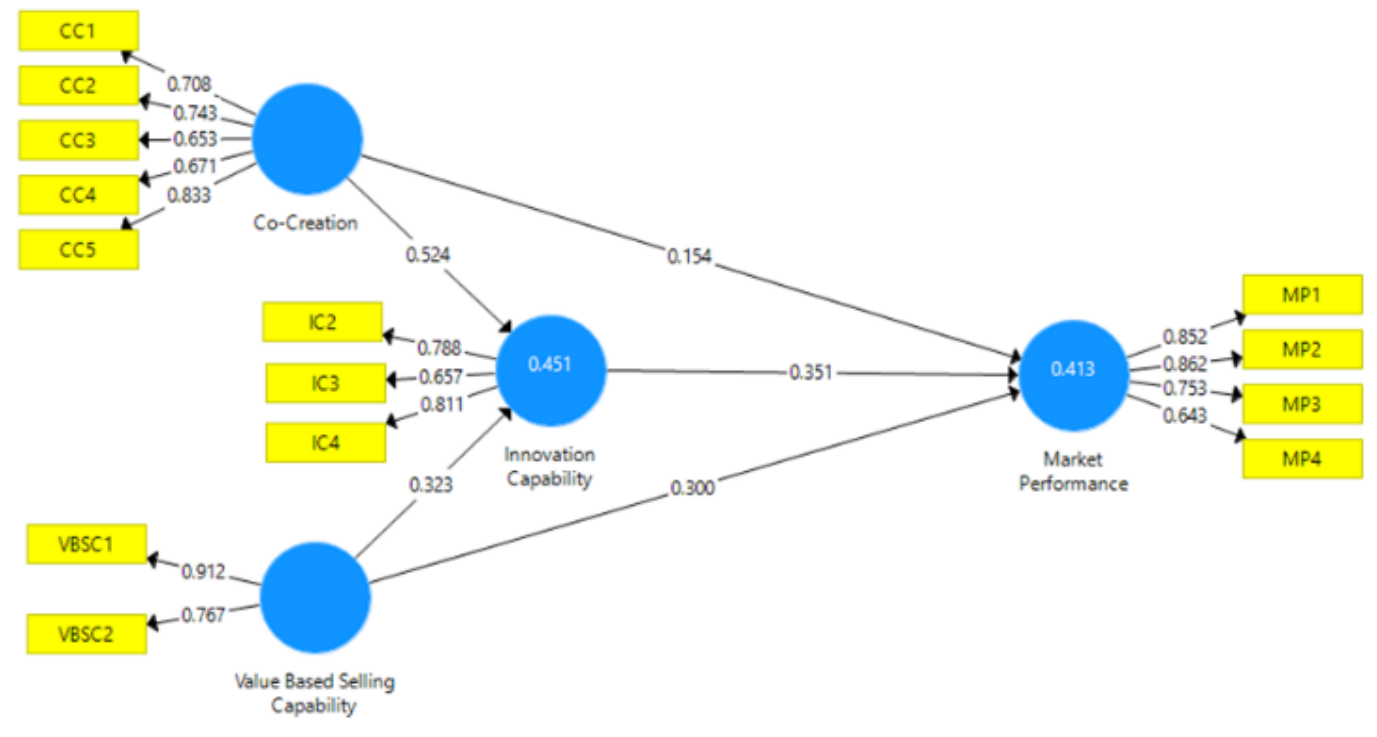

Fig. 1. PLS Output.

\section{Research Method}

This study applies a quantitative approach by using a survey method with the population is the entire guitar entrepreneur in Sukoharjo District. The sampling technique used is sampling purposive with certain criterion as follows: 1) owner of guitars SMEs, 2) Minimum have 3 workers 3 ) has been producing for 3 years, the number of samples as much as 60 people and willing to do interviews. This research uses SEM with 2 variables (independent) Co-creation (5 indicators) and Based value Selling (endoge2 indicator), with variable endogenous (dependent) and marketing performance (4 indicators). Measuring scale using questionnaires with a Very agreeable (5), agree (4), neutral (3), less agree (2), disagree (1). Data with analyzable is using SEM with SmartPLS 3.0.

\section{Results}

The research results of variable respondents of the innovation capability shows a majority of $73.3 \%$ expressed that the resulting guitar products were hard to be tested by competitors, and $8 \%$ declared neutral and $13.3 \%$ expressed less agreed to $13.3 \%$. Respondents had the ability to designed a diverse guitar product amount $98.3 \%$ expressed concur and $1.7 \%$ expressed neutral. Respondents also had an ability to do material development or raw material of the guitar as much as $56.7 \%$ stated, as much as 30\% expressed less concur and $13.3 \%$ 
expressed neutral and as much as $46.7 \%$ said it was able to adjust to the ever changing market conditions, amount $40 \%$ expressed neutral and $13.4 \%$ expressed concur.

Co-Creation variable shows most of the $95 \%$ stating the respondent has a bond or cooperation with the customer regarding the design example, the color comes from the customer's idea. In addition, as much as 5\% expressed less concur. Respondents mentioned having the ability to provide individual services or self-service to customers as much as $95 \%$ expressed consent and 5\% expressed disagree. Subsequently respondents had experience with as much as $80 \%$ of the customer-expressed consent, as much as $15 \%$ expressed disagreement and 5\% answered neutral. Respondents had the ability to collaborate with customers stating that the $81.7 \%$ agreed, less agreed as much as $15 \%$ and $3.3 \%$ expressed neutral. The participation of respondents in adjusting to meet market changes in cooperation of $50 \%$ has been adjusted to the market change, but as much as $43.3 \%$ expressed neutral and $6.7 \%$ disagree.

Value-based Selling variable majority respondents as much as $98.3 \%$ expressed agreeing to have the ability to regulate time value, during the production process of the produced product and $1.7 \%$ declared neutral. Respondents have a business value for the production process as much as $93.3 \%$ expressed their consent and as much as $6.7 \%$ expressed neutral. Most of the respondents had an ability to set cash for the production process as much as $75 \%$ expressed consent, as much as 15\% expressed less concur and 10\% expressed neutral. Respondents have an ability obtained the value of the resulting product $100 \%$ concur agreed and the respondent has the ability to build trust that is given customers with good total $100 \%$ expressed concur.

Marketing performance variables, most respondents as much as $90 \%$ expressed their consent to the growth in the value of products having increased in the last three years and as much as $10 \%$ of neutral answers. Respondents as much as $76.7 \%$ expressed their consent to the number of sales experienced in the last three years and 23,3\% declared neutral. Respondents as much as $40 \%$ expressed less consent to an increase in the number of new customers, and as much as $35 \%$ declared neutral and $25 \%$ expressed concur.

This category of respondents by the majority of $95 \%$ gender is male and $5 \%$ female. Most of the respondents $43.4 \%$ educated in Junior High School and $40 \%$ educated in Elementary School as well as 16, 6\% educated in Senior High School. The length of business on most respondents was $78.4 \%$ running a business more than 12 years. A total of $16.6 \%$ between 7 and 11 years and 5\% advertised the business from 2 to 6 years.

\section{Discussion}

Hypotheses test results obtained the result of variable Co-Creation influential positive and significant to the innovation capability with the result of 0.524 . P value $0.001 \mathrm{H} 1$ received that the better Co-Creation will be the higher capability Innovation that Co-creation Positive effect on variable Co-Creation positively effect on marketing performance with results 0.154 . $\mathrm{P}$ value 0.005 , hypothesis 2 received, the increasing Co-Creation will be In line with the research from Farida [22] mentioned that co-creation has positive and significant effect on hypothesis 3 marketing performance shows that there is a value based selling influence on innovation capability showing positive and significant results with 0.323 results and $\mathrm{P}$ value 0.002 . Hypothesis 4 is the influence of value based selling capability on marketing performance, the higher the marketing performance will be with the results 0.300 and $\mathrm{P}$ value 0.007 . 
The findings from Töytäri and Rajala [3] mentioned that creating superior customer value and ability in managing the sales resources can remain in the competitive market. In addition, there was an influence on the innovation capability of marketing performance that show positive and significant results with 0.351 results and $P$ value 0.007 . This is in accordance with the results of the research conducted by Nguyen et al. [23] mentioned that the capability of innovation has significant effect on the marketing performance and results findings from Carraresi et al. [24] stated that the capabilities of innovation have a positive and significant impact on marketing performance.

\section{Conclusion and Suggestion}

Findings of this research show that co-creation variables that have ties with customers, self-service, ability, provide experience, collaborate and be able to deal with market changes that can improve the marketing performance of the lowest results is a variable co-creation to marketing performance.

Research findings of value based selling variable related to respondents capable of directing the value of time, business value, and cash flow value, create value of customers and build trust with customers so that it can improve the marketing product performance. These suggestions for innovation capabilities need to be improved for small business owners to always keep up with the developments related to design, color and quality according to customer needs. The limitation in this study is that respondents of medium small business owners are not distinguished between small and medium enterprises in only one area of Baki sub district, for forthcoming research can be done by increasing the number of respondents in the wider scope at the district level, with the analysis techniques used more comprehensively with SEM-AMOS analysis.

\section{References}

[1] S. C. Collinson and R. Wang, "The evolution of innovation capability in multinational enterprise subsidiaries: Dual network embeddedness and the divergence of subsidiary specialisation in Taiwan," Res. Policy, 2012.

[2] M. Colurcio, M. Melia, S. Care, and A. Verre, "Value Co-Creation in the IoT Era," 5th Naples Forum Serv., 2015.

[3] P. Töytäri and R. Rajala, "Value-based selling: An organizational capability perspective," Ind. Mark. Manag., 2015.

[4] M. Kavanagh, B. Walther, and J. Nicolai, "Hearing the hearing-impaired customer: Applying a job-based approach to customer insight discovery in product innovation in the implantable hearing solutions market," J. Med. Mark., 2011.

[5] R. Aryanto, A. Fontana, and A. Z. Afiff, "Strategic Human Resource Management, Innovation Capability and Performance: An Empirical Study in Indonesia Software Industry," Procedia Soc. Behav. Sci., 2015.

[6] C. P. Blocker, J. P. Cannon, N. G. Panagopoulos, and J. K. Sager, "The role of the sales force in value creation and appropriation: New directions for research," J. Pers. Sell. Sales Manag., 2012.

[7] C. K. Prahalad and V. Ramaswamy, "Co-creating unique value with customers," Strateg. Leadersh., 2004.

[8] N. Farida, A. Naryoso, and A. Yuniawan, "Model of Relationship Marketing and E-Commerce in Improving Marketing Performance of Batik SMEs," J. Din. Manaj., 2018. 
[9] N. Farida, "Determinants of Marketing Performance: Innovation, Market Capabilities and Marketing Performance," J. Din. Manajemen, Vol 7, Iss 1, Pp 59-65 VO - 7, 2016.

[10] J. Wiklund and D. Shepherd, "Knowledge-based resources, entrepreneurial orientation, and the performance of small and medium-sized businesses," Strateg. Manag. J., 2003.

[11] E. Duncan, C. Jones, and A. Rawson, "The truth about customer experience," Harv. Bus. Rev., 2013.

[12] K. H. Tsai, Y. C. Liao, and T. T. Hsu, "Does the use of knowledge integration mechanisms enhance product innovativeness?" Ind. Mark. Manag., 2015.

[13] B. Lawson and D. Samson, "Developing Innovation Capability in Organisations: A Dynamic Capabilities Approach,” Int. J. Innov. Manag., 2001.

[14] T. Cleff and K. Rennings, "Determinants of environmental product and process innovation," Eur. Environ., 1999.

[15] D. O'Sullivan and A. V. Abela, "Marketing performance measurement ability and firm performance," J. Mark., 2007.

[16] X. Zhang and R. Chen, "Examining the mechanism of the value co-creation with customers," Int. J. Prod. Econ., 2008.

[17] R. Whiteley and D. Hessan, "Customer-centred growth: five strategies for building competitive advantage," Manag. Serv. Qual. An Int. J., 1996.

[18] N. Farida and E. Ardyan, "The driving of customer loyalty: Relational approach, perceived value and corporate image," Int. J. Bus. Soc., 2018.

[19] P. Töytäri, T. B. Alejandro, P. Parvinen, I. Ollila, and N. Rosendahl, "Bridging the theory to application gap in value-based selling," J. Bus. Ind. Mark., 2011.

[20] W. Hung, C. C. Lu, and C. F. Lee, "Mutual fund herding its impact on stock returns: Evidence from the Taiwan stock market," Pacific Basin Financ. J., 2010.

[21] M. Alexander and E. Jaakkola, "Customer Engagement Behaviours and Value Co-creation," Cust. Engagem., 2015.

[22] N. Farida, "Antecedent of innovation and marketing performance in Batik industry," Adv. Sci. Lett., 2017.

[23] B. Nguyen, X. Yu, T. C. Melewar, and J. Chen, "Brand innovation and social media: Knowledge acquisition from social media, market orientation, and the moderating role of social media strategic capability,” Ind. Mark. Manag., 2015.

[24] L. Carraresi, X. Mamaqi, L. M. Albisu, and A. Banterle, "Can Strategic Capabilities Affect Performance? Application of RBV to Small Food Businesses," Agribusiness, 2016. 